\title{
Marcel Proust, Cahier 53
}

\section{Davide Vago}

\section{(2) OpenEdition}

\section{Journals}

\section{Edizione digitale}

URL: http://journals.openedition.org/studifrancesi/1603

DOI: $10.4000 /$ studifrancesi. 1603

ISSN: 2421-5856

\section{Editore}

Rosenberg \& Sellier

\section{Edizione cartacea}

Data di pubblicazione: 1 novembre 2014

Paginazione: 630-631

ISSN: 0039-2944

\section{Notizia bibliografica digitale}

Davide Vago, « Marcel Proust, Cahier 53 », Studi Francesi [Online], 174 (LVIII | III) | 2014, online dal 01 novembre 2014, consultato il 18 septembre 2020. URL : http://journals.openedition.org/studifrancesi/ 1603 ; DOI : https://doi.org/10.4000/studifrancesi.1603

\section{Questo documento è stato generato automaticamente il 18 settembre 2020.}

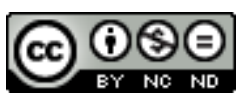

Studi Francesi è distribuita con Licenza Creative Commons Attribuzione - Non commerciale - Non opere derivate 4.0 Internazionale. 


\title{
Marcel Proust, Cahier 53
}

\author{
Davide Vago
}

\section{NOTIZIA}

MARCEL PRoust, Cahier 53, édité par Nathalie MAURIAC DYeR, Pyra WISE, Kazuyoshi YosHIKAWA, Turnhout, Bibliothèque Nationale de France/Brepols Publishers, 2012 («Cahiers 1 à 75 de la Bibliothèque Nationale de France»): volume I: Fac-similé, pp. XI + 209; volume II: Transcription diplomatique, pp. XL + 253.

1 Il Département des Manuscrits della Bibliothèque Nationale de France possiede un tesoro non ignoto agli studiosi di Proust di tutto il mondo: i settantacinque quaderni (Cahiers) nei quali Marcel Proust ha ideato e sviluppato la sua monumentale opera fin dal progetto del Contre Sainte-Beuve (1908). Grazie alle tecnologie attuali, la Bibliothèque Nationale de France ha deciso di renderli disponibili al pubblico in una collana prestigiosa, affidata a una équipe internazionale di généticiens, esperti dei manoscritti de À la Recherche du temps perdu diretti da Nathalie Mauriac Dyer (responsabile dell'équipe Proust all'ITEM - Institut des Textes et Manuscrits modernes). Tale progetto prevede, per ognuno dei Cahiers, la pubblicazione integrale del manoscritto proustiano, in un doppio formato: nel volume I è proposto il facsimile del Cahier manoscritto, a partire dalla versione digitalizzata dello stesso; il volume II ne presenta la trascrizione diplomatica, al fine di facilitarne la lettura o la consultazione.

2 Il volume I del Cahier 53 presenta una succinta ma precisa «Description matérielle» del manoscritto in questione (pp. VI-X), seguita dal «Fac-similé critique du Cahier 53», a colori. I curatori del volume hanno altresì ritrovato alcune pagine o frammenti che Proust ha staccato o ritagliato dal Cahier 53 e inserito in altri Cahiers manoscritti, nella fase di "montaggio" della sua opera: la sezione «Fac-similé des pages des Cahiers VII, VIII et IX contenant des fragments du Cahier 53» (pp. 169-193) presenta tali ritrovamenti. Al fine di facilitare la lettura del manoscritto, il volume si chiude con un «Diagramme des unités textuelles du Cahier 53» (pp. 195-207): una rappresentazione schematica delle 
pagine del facsimile, su cui appaiono indicazioni alfanumeriche progressive che orientano il lettore nella fase di consultazione.

Il volume II presenta una dettagliata «Introduction» (pp. xXI-XL) in cui si avanzano ipotesi comprovate sulla datazione e sulla cronologia della redazione del manoscritto. Redatto all'inizio della Grande Guerra, probabilmente verso il 1915, il Cahier 53 rappresenta la versione primitiva de La Prisonnière (il tomo V della Recherche). I curatori analizzano altresì l'ossatura del manoscritto, che ha il suo perno nell'evocazione di risvegli mattutini successivi del protagonista (struttura ereditata dal primitivo progetto del Contre Sainte-Beuve). La fedelissima «Transcription du Cahier 53» (pp. 1-168) permette, anche al lettore impreparato di fronte alla calligrafia di Proust, di cogliere tutto il dinamismo della sua scrittura. Nelle cospicue pagine delle «Notes» (pp. 169-232) e nell'altrettanto minuziosa «Analyse» finale (pp. 233-242), vengono chiariti anche numerosi riferimenti culturali contenuti nel manoscritto. 